\title{
The Application of Cloud Computing in Virtual Enterprise's Information Resources Sharing
}

\author{
Wei Wang ${ }^{1}$, Guan-Quan Liu ${ }^{1}$, Qiu Zhang ${ }^{2}$ \\ ${ }^{1}$ College of Management, Qingdao university of science, Qingdao, China; ${ }^{2}$ Business school, Qingdao university of science, Qingdao, \\ China. \\ Email: weiwang901012@126.com
}

Received 2013

\begin{abstract}
With the rapid development of social,science and technology ,we are always looking for the advanced and rapid manufacturing method and the management pattern.thus a new enterprise cooperation pattern-Virtual Enterprise arises at the historic moment. The cooperation is a process which advantages the temporary enterprise resources each other. Therefore, the virtual enterprise must encounter the problem that how to realize the virtual enterprises' information resources sharing and improve the efficiency of enterprise cooperation. This paper uses the cloud computing's advantage to solve the problem of virtual enterprise information resources sharing. Then enterprise is able to share the information of different regions,different computing environment and improve the efficiency of virtual enterprise cooperation.
\end{abstract}

Keywords: CLOUD Computing; Virtual Enterprise; Information Sharing

\section{Introduction}

In the uniform and competitive market, the virtual enterprise slowly becomes an important enterprise management mode.Most of the virtual enterprises are constituted with the conventional enterprises which distribute in different regions and countries. They use the information and Internet technology to rapidly response to the demand and change of the market and set up the dynamic alliance. Therefore, the virtual enterprise is discrete, dynamic and cooperative, these characteristics show the very important relationship between information sharing and the successful operation of virtual enterprise.But these characteristics make the virtual enterprise meet with the problem that the different information systems cause information transmission hindered,data loss and the dilemma that parts of hardware and software update causes the useless of information. It will lead the relevant information system of virtual enterprise to be low efficiency, more waste of manpower and material resources. It will result in serious economic loss. Therefore, the internal effective cooperation of team members relies on that the different system environment, different regions, different organizational structure and operation mode of the enterprises realize effective information sharing. So we should effectively solve the problem of information sharing of virtual enterprise. Improving the capacity of virtual enterprise partners' cooperation, reducing the management cost and enhancing its market competitive- ness are beneficial for developing the wider profit space [1].

At the end of 2007, Google and IBM present the cloud computing in their cloud computing plans. Cloud computing develops very fast, at present, some cloud computing's service is used. If the cloud computing are applied for information resources sharing in virtual enterprise, it will greatly improve the capability of information resource sharing. The development of economic, enterprise culture, science and technology technology, network environment are huge differences in alliance enterprises. It will lead the information resource distribution and requirement level of alliance enterprises to be great difference . Therefore, raising the efficiency of information resources sharing, and satisfying all alliance enterprises' information demand are important for virtual enterprises' succeed. Well, cloud computing uses distributed computing, virtual technology and utility computing to expand the scope of the resource sharing, so long as the network is continuous, we can use and access alliance enterprises' information resource anywhere and any time; It uses utility computing to measure, customize, lease . It does not only save the resources, but also realize the residual resources sharing, make maximum use of the information resources and improve the efficiency of sharing. To virtual enterprises' information resource sharing ,cloud computing are revolutionary technology, it is just like the water, electricity which we use and take with convenient everyday. By the computer or cell phone ter- 
minal equipment, alliance enterprise can enjoy the information resources which are provided by cloud computing at any time, any place ,if they have the Internet .

\section{The Related Theory}

\subsection{Cloud Computing}

Cloud computing is a revolutionary innovation in IT technology field .By managing, integrating, allocating computing resources which distribute in various network , cloud computing provides services to a large number of users at the same time in a unified interface, users don't need to know how to manage infrastructures which support the cloud computing, only need to pay for the function their use. It can reduce the investment in hardware, software and professional skills [2].

1) The top layer is the application layer .Software vendors will unitarily put the application software on the remote data center server or server cluster. Users can use the services according to which they need. This layer mainly cater to users. The so-called cloud computing is IT services. By the centralized data center, it provides flexible calculation, extensible, application and stored program and other services to the user .

2) The middle layer is the platform layer. It provides application services to cloud computing's applications and provides integrated development environment and hardware resources to users. This layer is mainly oriented for network application developers and programmers. To them, cloud computing is an Internet scale operation environment or software development platform.

3) The bottom is infrastructure layer. It is a distributed data center service which is linked by network and a very flexible based structure. It requires infrastructure providers and managers to make services to be center.It offers predefined,optimization and standardized infrastructure to satisfy users' application demand. The providers are responsible to manage the hosting services and applications which users choice. This layer is mainly faced to managers and provider, for them, cloud computing is center infrastructure which carries on the large-scale, distributed, link data by the network.

\subsection{Virtual Enterprise}

Although the development of virtual enterprise has been a long time, a unified definition had still not appeared at present. We can see many similar concepts about virtual enterprise in the documents, such as dynamic alliance, virtual company, enterprise integration, virtual organization, expand enterprise, e-commerce, supply chain management, network organization and so on.

\section{Application}

\section{Plantform}

\section{Infrastructure}

Figure 1. Three layer architectures of cloud computing.

Nowadays,there are several typical definitions as follows:

Definition 1: Byrne. J.A thinks that"virtual company is constituted with independent companies suppliers, customers, or even competitors, they share skills and cost, go into each other's market by the connection of information technology .It does not have central office or organization chart. It also does not have vertical integration and levels"[3].

Definition 2: Qi Er-Shi proposes that"virtual enterprise is comprised with some legal persons who have the core competence, it treats network technology as the main operation means, it is a temporary enterprise alliance which can realize the resources sharing and share risks in the fierce competitive market"[4].

I think that virtual enterprise is setted up with two or more independent enterprise temporary which point to to seize the fleeting market opportunities and adapt to changed market environment, by the Internet, they contribute their own core ability to share resources, cost and risk, they cooperate with each other to realize the scheduled target. When the task is completed, the virtual enterprise will collapse.

\section{The Pattern Design of Virtual Enterprises' Information Resource Sharing Based on Cloud Computing}

The model of virtual enterprises' information resource sharing based on cloud computing, which put the information resources of various alliance enterprises together. It uses the mixed cloud to realize mutual operation between private clouds and public cloud, then enhances the efficiency of virtual enterprises' information resources sharing and makes the virtual enterprise have a better development. It can generally be divided into information resources sharing platform and cloud access platform.

\subsection{The Platform of Virtual Enterprises' Information Resources Sharing}

The platform of virtual enterprises' information resources sharing is mixed cloud. The private cloud is each alliance enterprise. Private clouds is managed by each 


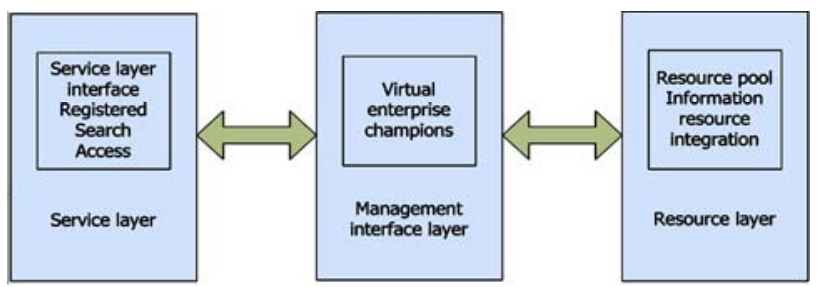

Figure 2. The model of virtual enterprise information resource sharing based on cloud computing.

enterprise.The public cloud is constituted with private clouds and managed by the champion of the virtual enterprise.

The platform model of Information resources sharing is constituted with service layer, interface management layer and resources layer. As shown in Figure 2, the service layer is on the left, it is the information resources sharing layer. This layer mainly provides platform to realize information resources sharing. Middle layer is between service layer and resource layer, it is the core layer of realizing information resources sharing. This layer is primarily responsible to manage the information resources in public cloud,many application missions and scheduling. so that it can enhance the efficiency of the information resources and use safely. The information resources pool layer is on the right side. Information resource pool layer is a resource pool which includes the information resources of the alliance enterprise . Its purpose is to integrate different information resources. Alliance enterprise mutual consult with each other and come up with the standardization of information resources.

Public clouds describes all kinds of information resources which are provided by each layer provides and establishes the index library for information resources. According to the needs of the application, alliance enterprises can search in the index library . Because of many information resources,the index library must be understanded by people and machine, so that it can improve the efficiency of using alliance enterprise information resource[5].

\subsection{Establish Cloud Access Platform}

Establishing an effective cloud access platform can make the information resources sharing be more effective and fully utilized. At the same time, alliance enterprises can simply and quickly login to information resource sharing "cloud". Establishing cloud access platform should accord to the requirements of the relevant information resources sharing.On the one hand, access platform can be well and easy to access, and it can help alliance enterprises complete inquiry, register, and access .The operation should be simplified, each alliance enterprise can access information resources "cloud" anytime, anywhere . On the other hand, access platform must be safe. It can help the champion of virtual enterprise identify the login's identity and prevent illegal operation and illegal intrusion.

\section{Summarizes}

Virtual enterprise is the development direction of the future enterprise organization model. With the widespread application of the virtual enterprise, It has become the focus in the study of virtual enterprise that how to improve the efficiency of the virtual enterprise information sharing and ensure the normal operation of virtual enterprise. This paper effectively combines cloud computing with virtual enterprise information sharing to make the virtual enterprise be more freedom in the cloud environment, to share information resources in the more extensive space and provide effective information resources for the alliance enterprise fastly. It makes a foundation for the development of the virtual enterprises.

\section{REFERENCES}

[1] Zhao Qiang,Xiao Ren-Bing.The Virtual Enterprise Information Sharing of the Game Theory and Mechanism Design [J] Computer Integrated Manufacturing System, 2007, 13(8):1566-1571

[2] Zhang Jian-Fen.Cloud Computing Will Finish the Information Resource Sharing [J].Modern Information, 2010, 30(12):49-50

[3] John A .Byrne.The Virtual Corporation[J] Business Week, 1993, (8):36-41

[4] Qi Er-Shi.Huo Yan-Fang.Development Research Review of the virtual enterprise[J].Manufacturing Technology and Machine, 2004,(9):37-41

[5] Bi Chang-Quan.Cao Jian. Wu Wei-Hua, Wang Yan-Hong. The Pattern Design of Tang Shan Information Resource Sharing Based on Cloud Computing [J].Journal of He Bei University, 2012, (1):97-99 